referred to the work of the College of Technology in Liverpool in conjunction with ourselves in London River and supported by the National Ports Council. The computer programme for the model port is based on the conditions obtaining in London and its approaches, and has been shown to be a perfectly viable programme which has worked very well on our main P.L.A. computer during simulated and live traffic comparison runs.

We need to disengage the straight hardware of Brandenburg's subject from the natural interest that surrounds it to see the true meaning of the new look in philosophy that it introduces to the marine stage; another Brandenburg concerto and a welcome sound.

His comments on legislative means were perhaps over simplified, for this brings us face to face with some of the oldest conventions known to man. A lot of case law and mumbo-jumbo will have to be cleared away first. Admiralty Courts have only accepted decisions reached by the man, albeit helped by various aids. Now they will have to accept that the man is monitoring the black box and acting on its directions. If these are truth, measured and quantified, how can he reasonably do otherwise? For some time this has been the situation for aircraft, - so can the patriachs claim that the sea captain is all that different in culture and intelligence from the air captain; his run up to the waterway is exactly analogous to the glide path of the aircraft; the flare-out in each case is left to the man in charge. Yet some people go to great pains to repeat that there is no similarity at all between ship and aircraft movements and safety. The inhibitions of the one are often the opportunities of the other, but no rational thinking can rule out any similarity at all on that count: the aircraft can climb, the ship cannot; the aircraft cannot stop, the ship often can; and so forth. I believe that the philosophies of the two modes of transport are entirely compatible; both in reality require no more than traffic management or control as Brandenburg calls it. The safety of air traffic does not depend very much on the third dimension we hear so much about-it depends on precise order and conformity within established lanes and corridors. It would seem that the only time the air traffic people get into real trouble is precisely when they are using the third dimension, when they are descending or climbing in or out of terminal areas. There is a lesson here, for those who want to learn it, in the sea context and the world cries out for it. Only convention holds us back and it seems to me that the marine side is now going through precisely the same argument that the air traffic people went through in the late forties and fifties. What are we going to do about it?

\title{
Navigational Discipline at Sea
}

\author{
Captain P. A. Thompson
}

Ir is doubtful if at any period in the history of seafaring a greater effort has been made to organize the safe conduct of ships about the seas than that which is being made today, and it is equally doubtful if the need was ever more urgent. At the present time a large amount of thought and work is being put into the task of trying to formulate rules and systems aimed at providing for the safer navigation of vessels at sea. Excellent ideas have been proposed for conduct in traffic, such 
as those put forward by Dr. Calvert, Admiral García-Frías and many others, which, together with the systems of traffic separation which have been established in areas of heavy shipping concentrations, could bring about a decrease in the present rate of marine casualties. However, all this effort will be of no avail unless there is a marked upward trend in the standard of seamanship-particularly watchkeeping-and the introduction of some means of penalizing vessels which do not conform to the rules without a very valid reason, irrespective of whether or not they are directly involved in an accident. If we are to proceed about our business at sea in safety a proper discipline with regard to the rules is essential.

A recent survey ${ }^{1}$ has shown that a number of the ships transitting the Dover Strait are ignoring the recommendations about routing in this area. Were similar surveys to be carried out in other places where 'traffic lanes' have been laid down and recommended, it is highly probable that a similar picture would emerge. The South African Coastal Route is an example of a scheme which is only complied with by a percentage of the passing ships; the rest apparently go as they please. Such disregard for a system designed to increase safety, and maintain efficiency, can not only bring the idea into disrepute but also cancels out the economic benefits to be derived from its use by all vessels, especially in conditions of reduced visibility.

As an example of the situation which can be met with in the Strait of Hormuz at the Persian Gulf entrance, an area of shipping concentration (including a high proportion of large tankers) and for which Admiralty charts are already in use with the routing lanes printed in. On the night of 2 August between 2300 and 2400 hours local time we plotted five inward-bound vessels using the outwardbound lane. Four of them were observed to be tankers as was the fifth if size is any guide. A conversation was overheard, on v.h.f. radio, between one of these vessels and an outward-bound vessel who asked if the inward ship was aware that traffic lanes existed in the area; the offending vessel admitted quite openly that he knew of the arrangement. It can only be assumed that he had no intention of observing the routing procedure.

It must be presumed that when ships ignore arrangements to facilitate safer navigation their actions must be condoned by the operators of the ships, or the practice would not continue. Doubtless many of them feel that the economic advantages to be gained from corner-cutting outweigh the other aspects, although the economies achieved must be of a very minor order when compared with the costs of accidents. Were the operators of all fleets to take steps to ensure that the vessels under their control complied with 'recommended routing' there would be little incentive for individual ships not to follow the general pattern.

Critical comments on the standards of today's seamanship are being made with increasing frequency, cases have even been quoted of failure to keep a proper lookout. At a recent enquiry 2 held in London, it was revealed that despite clear weather one of two ships involved in a collision had not observed the other until very shortly before the moment of impact, and that no lookout had been posted to assist the watchkeeping officer-who was uncertificated. My own ship had experience of this type of incident during a recent passage into the Persian Gulf. At 0935 hours local time we were proceeding westbound in clear weather and just south of Jazireh Qais and Lavan Island; we were overtaken, at 2 to 3 knots, by a Liberian flag tanker (Chrysanthy $M$. Lemos) of similar size to ourselves (2 10,000 tons, dwt.) from fine on the starboard quarter, our courses converging 
at approximately $10^{\circ}$. As a close-quarter situation was becoming imminent, and the other vessel gave no sign of altering, we had to sound five short blasts and take avoiding action. As a vessel of our size must be a fairly conspicuous target in clear daylight, it can only be assumed that no lookout was being kept by the other vessel, or that the watchkeeper had no knowledge of the Rule of the Road. As a further instance of the attitude of many seamen to the Rules, during a North Sea passage in May, in poor visibility (I mile) during which we passed through some heavy traffic and had a number of close-range passings, it appeared that only the occasional vessel was sounding the regulation sound signals as specified by Rule I 5 .

The term 'radar morons' has been used to describe those who manœuvre ships in traffic and reduced visibility on the basis of inadequate information, and is fair comment, but it should be appreciated that these same 'morons' are loose upon the seas and handling ships in clear weather. They do not suddenly change, either in attitude or capability, when the weather changes. Are these people really so irresponsible or is it that they know that little can be done about their actions unless they have an accident ?

The question of training was raised at an Institute meeting in February ${ }^{3}$ and warrants more attention than it appears to get. Most trained personnel have also been indoctrinated to ensure their correct approach to the problem of traffic avoidance, but there are a very large number of watchkeepers who have not had proper training. A large amount of very expensive equipment has been fitted in ships as an aid to safety, but this equipment will be of little advantage without suitably trained and qualified watchkeepers to interpret the information made available, and to make the decisions. The even more sophisticated radars ${ }^{4}$ which are now coming on to the market, and which include a large measure of automation, are still dependent on the observer in the final phase and the more sophisticated this type of apparatus becomes, the better the training required in order to realize its full potential. Improved instrumentation is not the answer to today's traffic problem; the watchkeeper, the weak link in the chain, must also be brought to a higher standard. It would seem to be a matter of the greatest urgency that both training and the acceptance of navigational discipline be given a high degree of priority if new rules and systems are to be successfully implemented.

The system of surveillance which is being inaugurated by patrol craft and radar for the Dover Strait region will be a first step towards the introduction of traffic control for regions where the voluntary principle is proving inadequate for the circumstances. If this idea of overseeing traffic-flow proves to be the answer, then it could be extended and applied to other 'black spots'. This would then leave outstanding the matter of dealing with offenders in places outside the scope of such controls. For these the alternative would seem to lie in the settingup of a clearing-house to handle complaints from various sources, including ships, concerning the failure of vessels to observe the rules or for behaving in a manner likely to be an embarrassment to navigation in any other way. An organization of this sort would be able to 'short list' habitual offenders, whether ships or individuals, and in addition to reporting them to their own governing authority, could also provide background information should they be involved in an accident at any time, or become a party to an enquiry.

Much has been said and written regarding the standards of 'flag of convenience' ships, and although they are not the only offenders, a large proportion of com- 
plaints appear to be directed at them. It would also appear that a majority of these offenders are manned by members of one particular nationality.

Today's low safety record is due almost entirely to the failure of man himself. Standards of manning and seamanship appear to be suffering from a steady deterioration, and with the increasing number, size and speed of ships the outlook is becoming a matter of increasing concern. Whether this lowering of standards is due to ignorance on the part of seamen, or to their rejection of the principle of traffic discipline, is not the important factor. What is important is that such people are permitted to carry on, endangering the lives and property of others with comparative immunity-in terms of road traffic it would mean that it was no offence to drive on the wrong side of the road unless a person or another vehicle was struck.

The present rules are not at fault and new rules will not be of any advantage until means can be found to impose the necessary compliance, and to make non-compliance unprofitable to both the seaman and the vessel's operators or owners. If these means cannot be adopted then any hopes for an improvement in the record of accident statistics in the future are unlikely to be fulfilled.

\title{
REFEREN CES
}

1 Beattie, H. H. (1971). Traffic flow measurements in the Dover Strait. This Journal, 24, 325 .

2 Allegro/Pacific Glory Enquiry.

3 Captain Arthur of British Rail, at the Committee Meeting held in London on 3 February 1971. This Journal, 24, 242.

4 Wylie, F. J. (I970). An examination of some ship radars with automatic computation. This Journal, 23, 373.

\section{Collisions Involving Very Large Ships}

\author{
J. Watt \\ (Marconi Communication Systems Ltd.)
}

Commander P. C. H. Clissold, in a contribution to Forum in the April 1971 issue of the Journal, makes a point concerning the collision-avoidance handling of very large single-screw ships. Commander Clissold writes:

'Because of their unwieldiness an avoiding action must be initiated while still at a considerable distance from the threat, if it is to have any effect. This distance is beyond that at which the eye of the navigator can accurately assess the risk of collision or the need to manœuvre. He must, therefore, depend upon instrumental information for making his decisions; in other words, in clear weather as in thick, he must use his radar and plot continuously if he is not to hazard his ship. If the argument is put forward that this will require two men on watch together and the state of manning does not permit this to be done, the answer is that a change in organization must be made to make it possible.'

I would agree with Commander Clissold as to the great amount of additional information provided by a continuously maintained plot; and as to the potentially 